\title{
ON THE ISSUE OF FINANCIAL SUSTAINABILITY DEVELOPMENT IN A REGION
}

The paper deals with the issue of financial sustainability of a regional economic system. Interpretation of the category of financial sustainability is given in its interrelation with economic stability. The paper also suggests a tool for quantitative assessment of financial sustainability of a region, which takes specific features regarding generation of basic parameters of regional financial state into consideration.

Management efficiency in reference to regional development is determined to a large extent by a way continuously arising problems referred to functioning of regional socioeconomic systems are solved, and also by efficiency in terms of generation of local models for economic interactions. In this case management mobility, being one of the prerequisites, cannot lag behind the evolving development conditions by virtue of the fact that the concern regarding efficiency attainment is associated with the actions aimed at using opportunities of the present situation.

Nowadays relationship between the level of regional development and the quality of solutions by regional authorities has got markedly stronger, as well as efficiency of economic structures' functioning has become more dependent on regional management qualification. The given conditions required an adequate response by regional management structures to the dynamic change in the situation resulted in expansion of their economic independence.

Under such conditions significance of an issue referred to securing sustainability of regional economic system functioning increases, and development of both single applied tasks and theoretical fundamentals for economic activity sustainable results becomes urgent. Solution of the issues related to the given aspect is possible, in our opinion, in terms of the classical theory of sustainability. At the same time sustainable socioeconomic development in a region depends upon joint influence of many factors, including their specific groups - environmental, sociopolitical and legal.

Until recently the issue of sustainability of a regional economy has not been given due 
consideration, in our opinion, and that is largely why methodological issues lack for proper development. Likewise, a conceptual framework for the theory of sustainability in terms of economic activity is not adequately worked out, an information base for investigation into the process of sustainability is not generated, and a set of cognitive means and research techniques does not exist. All the mentioned aspects of the issue require generalization and systematization of the available scientific groundwork. This work is important due to the fact that it affords an opportunity to consider the elements that form a basis for sustainability of a regional reproduction process, to measure quantitatively an effect total dynamics and to exert a dedicated influence upon an integral result generation.

In addition to the factors affecting economic growth, sustainable development is directly connected with reliability of the regional system economic structure and mobility of its functional constituents. Balance of the latter is a crucial condition for preserving stability of the final results, including the situations, when external perturbations increase.

Among the major sustainability constituents of regional economy as a whole are financial resources of a region and correlation among the sources of their formation. In general, modern development becomes more and more concerned with financial opportunities, although a financial source is of a particular nature and it does not directly constitute physical content of a manufactured product. Nevertheless, it is precisely the financial source that, being a determinative prerequisite, gives an impulse to activities the modern society will be engaged in. At the same time, being a kind of a super-resource constituent, a financial source belongs to the same extent to all life-support activity lines and it does not belong inseparably to any single segment of human activity. Simultaneously, being a universal tool, it is capable of bringing into action and defining the scales of any socially valuable activity. Due to the specific functions of financial resources within the reproduction system, they determine economic system development opportunities, growth rates and nature management expediency. Therefore, major output parameters of the human activity are systemically connected with finance, production elements, i.e. financial sustainability.

Introduction of the category of financial sustainability in the system of factors specifying development is motivated by the possibility to distinguish a specific aspect of a generalizing result by way of applying it. This category is undoubtedly in close relation to a final result of activity, but it reflects a cost profile of the result. It is the category, on the basis of which availability of actual conditions for economic system functioning and, thus, of the prospects for its activity can be judged. In this case the research into the category and methodological aspects of financial sustainability assessment is equally important both at a level of individual enterprises and a region as a whole.

Theoretically, financial sustainability is interpreted as an economic sustainability constituent and a prerequisite for securing economic balance of the production system. Thereby, individual researchers (A.N. Folomyov, G.Y. Rakitskaya, M.A. Fedotova) consider it better not to single out financial sustainability into an independent category, but to regard it "as an element of integral realization of a generalized property of a production and economic system". The given attitude is justified by the fact that the economic category is to reflect an essential aspect of the phenomenon as a whole and at the same time to reveal its inner nature.

The content of the category "financial sustainability" does not entirely coincide with the general notion of sustainability of an economic system by virtue of its appropriation: it specifies only financial results of economic management and hence is narrower than the general notion of sustainability. At the same time, it is a part of the whole. Financial sustainability has a purpose - to reproduce the state of the economic system through the finance movement; along with that, regional financial sustainability by itself as well as the economic system as a whole are rather the result of self-generating functioning of the economy and availability of an efficiently organized financial system. As a consequence, an approach that implies satisfaction of economic and social needs of the region at the expense of its own potential has dominating significance in terms of understanding of what financial sustainability is. At the same time, such understanding of financial sustainability of a region has logically a broader interpretation. A region may theoretically have a financially sustainable state even at a lack of its own financial resources (at the expense of transfers and other preferential external investments) to create economic conditions for securing normal reproduction activity, i.e. when financial opportunities in the region are sufficient only to satisfy minimum expenditures along with renewal of major economic parameters in invariable scales and exclusion of financial obligation debts.

Among the most essential aspects directly affecting financial sustainability of a region there are the factors shown in the figure.

Financial sustainability potential is associated substantially with growing incomes of enterprises 


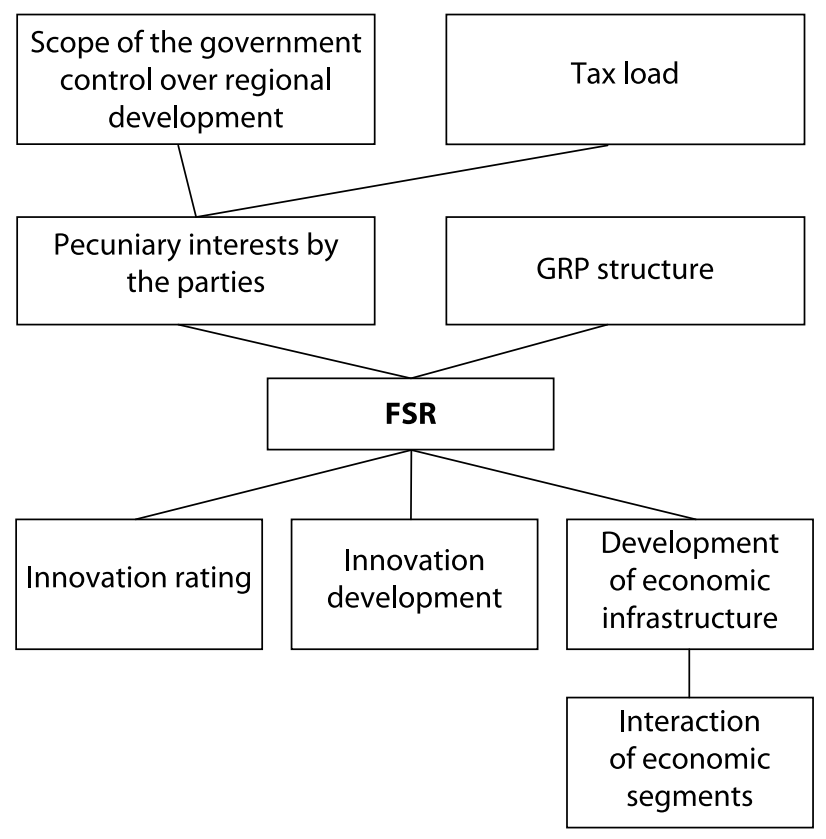

Fig. Major factors regarding financial sustainability of a region (FSR)

and the population that creates a taxation basis: the higher the incomes are, the more the budget returns are at the same level of taxation rates. As a result, an increase in taxable incomes of corporate entities and individuals creates a basis for financial sustainability in a region and reduces dependence of a regional budget on the federal one. Thus, financial stabilization of a region should imply functional appliance of financial stimuli and leverage that favour production growth and increase of incomes of business entities, including tax remissions. A regional strategy for securing financial sustainability is also associated with development by way of restructuring of the economy aimed at preferential production of high-technology products that have relatively high added value. Reproduction and out-regional deliveries (either interregional supply or exports) of principally mineral products (as in the present-day situation) result in unbalanced exchange in the view of expense effectiveness, since they have relatively low added value.

Financial state of a region is determined by final indices of activity in all economic segments and parameters of their economic management as well as by the results of activity at financial and equity markets. Consequently, a regional level of financial sustainability reflects both efficiency in terms of financial resource potential management and organization of market operations with values referred to the resource potential of the region. Thus, financial sustainability is affected by many presentday and expectable future factors. Therefore, calculation of its integral value, as applied to a region, is specific and simultaneously difficult from the standpoint of necessary information availability. And the character itself can be only relative, in our opinion. The matter is not only in the fact that its natural parameters are constantly changeable or tend to it, but also that neutralization of such changes commonly lags behind and it is possible only in part at each given period. Being a basic point, they destabilize the system by perturbing its functional state. As a result, single parameters lose their systemic flexibility and capability of functioning in the former mode thus affecting the net moment. Therefore, the financial management objective is to forecast and alleviate the given effect whenever possible and to make perturbation surmountable without considerable loss.

This is particularly important due to the fact that the modern civilization does not generally secure sustainable functioning of production systems. Nikolai Shilo, Member of the Academy of sciences once mentioned that "there are systems that belong to nonlinear ones, they are characterized first of all by their unsustainability. These are open systems fed by external energy, and this is a determinating factor in their evolution. For instance, nonlinear systems include economic, social and other ones...». Hence, if financial sustainability is the derivative of economic sustainability, then it can never be absolute, i.e. this state refers to a certain period of time and it is relative and collaterally subordinated by its nature. Consequently, financial sustainability cannot be attained at any cost (as well as twofold growth of the GDP by 2010) and it is reasonable only in case it fits in the general concept of sustainable development.

In order to identify financial state of a region and interactively monitor the process, indices specifying different aspects of regional financial state are applied. However, the given indices are not capable of determining a situation in general and in fact it is difficult sometimes to give an unambiguous interpretation of a situation. In particular, it is a complicated task to estimate financial status of a region when incomes and, consequently, expenditures show an increase during one period along with accounts payable growth, and vice versa, during another period when incomes and expenditures show a decrease along with accounts receivable growth, accounts payable are simultaneously reduced, etc. In this case contradictory nature of the economic situation makes it impossible to estimate a financial state integrally. For such an estimation an integral index is required, that is capable of providing a generalized situation relative to a certain period. 
Sustainable state of any regional economic system is in effect determined by existence and interaction of two constituents, namely, availability of reproduction potential and reliability of an economic structure of regional regulating systems. Efficiency of the latter is crucially affected by sensitivity and "flexibility of functional basic elements". This is also a prerequisite for preserving sustainability of final results, including the cases when destabilizing situations occur. Capability of a system to suppress growing impact of external perturbations, caused by crisis phenomena as well as by drastic change in economic relations and a new function of management structures, determines sustainability of resultant parameters and an integral index on the whole. By virtue of actual significance of the above-mentioned aspects there is a necessity in investigation of factors establishing a basis for sustainable functioning of a regional reproduction process. In this case it is also evident that balance of the pivotal elements makes it possible for the entire system to remain sustainable. The substantial elements within this range are financial flows within the regional system and relationship of the sources forming their actual scales within the bounds of the system.

What is important in practice is that identification of the tendencies in financial state changes allows not only to interpret the current state, but also makes it possible to forecast in many respects a future development path with preservation of the current conditions, to estimate significance of individual factors and to predict a result on much more substantial grounds. Thus, there is a way to influence the situation and bring a desirable final result. In this case financial sustainability is close by its objective to the character of the final results of the activity and it specifies cost relationship among the given results (A. S. Borgoyanov) as well as availability of conditions for functioning of the system in the long term.

It is likewise evident that financial state of an economic system, which enters a market with its own results, does not generally remain unchangeable over a long period of time. It is influenced simultaneously by many factors that have actually no sustainable dynamics in essence. First of all, such factors include market conditions, which might change within 24 hours, particular political bursts within and beyond the society, technological innovation breakthroughs etc. Each of them - individually and particularly in combination - is capable of modifying new dynamics of financial sustainability. Sensitive and flexible nature of market mechanisms may have a sufficiently operative influence on a sustainability integral value and change the present vector. Under such conditions a methodically consistent and quantitatively determined result specifying the vector of the financial state change is not only a basis for exposure of the general situation of the dynamics dependence, but also an opportunity to identify the elements creating it.

In addition to that, financial sustainability of a regional economic system, though being a basic constituent of the total result, it becomes absorbed by the results of all other scopes of activity in a region and it takes part in generation of an economic state integrated index. In this connection we consider that in order to calculate an overall result of financial sustainability $\left(\mathrm{FS}_{1}\right)$ in the region one should operate with the entire aggregate of regional financial resources in relationship to the cost result of the financial and economic activities expressed by the gross regional product (GRP) and debt parameters of the region defined as a difference between accounts payable and accounts receivable.

In our opinion, interrelation of the given parameters expressing financial and economic state of a regional economic system makes it possible, provided their functional stipulation is taken into account, to obtain a regional financial sustainability coefficient:

$$
F S_{1}=\underset{\left(F_{1}+F_{2}\right) / 2}{G R P} \times\left(\begin{array}{cc}
A r_{2}-A p_{2} \\
A r_{1} & A p_{1}
\end{array}\right),
$$

where $F S_{1}$ - financial sustainability coefficient of a region;

$G R P$ - gross regional product cost, in roubles;

$F_{1}$ and $F_{2}$ - financial resources at the beginning and at the end of the period, in roubles;

$A r_{1}$ and $A r_{2}$ - accounts receivable at the beginning and at the end of the period, in roubles;

$A p_{1}$ and $A p_{2}-$ accounts payable at the beginning and at the end of the year, in roubles.

In our opinion, the given relationship specifies an integral value of regional financial sustainability on account of the following: according to the formula, its logical structure involves, as a determinant, correlation of regional financial resources and the gross product volume on the assumption that regional activities can actually take place only at introduction of financial resources into an economic system as a starting factor. In this case simultaneous introduction of all three economic segments is required - state, business and households (population). This is a compulsory condition for putting available total potential of a region into operation.

There can be no doubt that an accumulated potential of production resources will "work" only under apparent conditions when regional 
interests are satisfied. Moreover, this is not the only initial incentive to action. The latter is completely impossible without acquisition of circulating assets at a production segment of reproduction and material conditions for labour potential operation. Thus, financial resources involved in a reproduction cycle take an immediate part in generation of economic results (GRP) and transform into a constituent part of its cost. Consequently, the less the volume of financial resources a certain result content (i.e. potential cost) is secured with, the higher the chances are to increase financial sustainability of a regional economic system. It should be mentioned therewith that reduction of specific expense of financial resources for a result and establishment of consolidation trend for financial sustainability is admissible only at unchangeable (or even increased) remuneration level of the equivalent amount of the labour consumed.

At the same time, an economic result is possible to be achieved (and most probably it was achieved in such a way) at the expense of borrowed (credit) resources. Likewise, a result is not free from an influence of development resources exported from a region (accounts receivable). In this case, if disbursement of a loan is more likely to decrease financial sustainability, accounts receivable have an opposite influence. Taking the given circumstances into account is provided in the formula by introducing "net" scores (a difference between accounts payable and accounts receivable, i. e., their correlation at the beginning and at the end of the period).

It should be mentioned that calculation of financial sustainability reliable parameters according to the procedure described above is impeded by the present-day practice of making up a regional financial balance, i. e., by the absence of complete account of financial resources related to all economic segments. In this respect there is a strong necessity in adjustment of the process of striking a balance in a region. Other indices applied for calculation of a financial sustainability index $\left(\mathrm{FS}_{1}\right)$ are estimated by statistics institutions.

In recent years, a number of works on the issue of estimation of economic system sustainable development have been published in the scientific literature. They differ from each other by their methods, principles and indices involved in the modelling process. Their principal propositions are based on consideration of processes regarding generation and allocation of financial flows at the level of macroeconomic systems, and they bear on the classical model of reproduction and public production accounting.

\section{References:}

1. Tatarkin A. I., Lvov D. S., Kuklin A. A. et al. Sustainable Development Modelling as a Prerequisite for Higher Economic Security in the Region. Ekaterinburg. Ural State University Publ. House. 1999. 276 p. (In Russian).

2. Potapov L. Financial Mechanism for Self-Development of a Region // The Economist. No. 6, 1999. P. 60-65. (In Russian).

3. Zorkova N. A., Vyshegorodtsev A. E. Sustainable Development of a Region: A Complex Approach to the Research // Man-Society-Environment: Collected Scientific Works. Pt. 1. Ekaterinburg. 2001. P. 137-139. (In Russian).

4. Kolesov A. S. On Integral Estimation of a Financial Situation with Budgetary Financing Objects // Finances. No. 6, 2000. P. 9-11. (In Russian).

5. Zakharchuk E. A. Financial Sustainability as an Index of Sustainable Social Development of the Region // Man-SocietyEnvironment: Collected Scientific Works. Pt. 1. Ekaterinburg. 2001. P. 230-233. (In Russian). 